Shyrokau, Barys; Wang, Danwei; Augsburg, Klaus; Ivanov, Valentin:

\title{
Vehicle dynamics with brake hysteresis
}

URN: $\quad$ urn:nbn:de:gbv:ilm1-2014210177

Published OpenAccess: October 2014

Original published in:

Proceedings of the Institution of Mechanical Engineers / D. - London : Sage Publ (ISSN 09544070). - 227 (2013) 2, S. 139-150.

DOI: $\quad 10.1177 / 0954407012451961$

URL: $\quad$ http://dx.doi.org/10.1177/0954407012451961

[Visited: 2014-10-14]

„Im Rahmen der hochschulweiten Open-Access-Strategie für die Zweitveröffentlichung identifiziert durch die Universitätsbibliothek IImenau."

"Within the academic Open Access Strategy identified for deposition by Ilmenau University Library."

„Dieser Beitrag ist mit Zustimmung des Rechteinhabers aufgrund einer (DFG-geförderten) Allianz- bzw. Nationallizenz frei zugänglich."

"This publication is with permission of the rights owner freely accessible due to an Alliance licence and a national licence (funded by the DFG, German Research Foundation) respectively."

\section{DFG}

Nationallizenzen 


\section{Proceedings of the Institution of Mechanical Engineers, Part D: Journal of Automobile Engineering}

\section{Vehicle dynamics with brake hysteresis \\ Barys Shyrokau, Danwei Wang, Klaus Augsburg and Valentin Ivanov originally published online 16 August 2012 \\ DOI: $10.1177 / 0954407012451961$ \\ The online version of this article can be found at: \\ http://pid.sagepub.com/content/227/2/139}

Proceedings of the Institution of Mechanical Engineers, Part D: Journal of Automobile Engineering 2013 227: 139

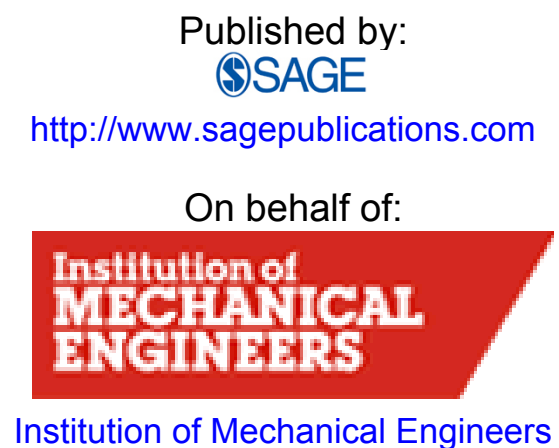

Additional services and information for Proceedings of the Institution of Mechanical Engineers, Part D: Journal of Automobile Engineering can be found at:

Email Alerts: http://pid.sagepub.com/cgi/alerts

Subscriptions: http://pid.sagepub.com/subscriptions

Reprints: http://www.sagepub.com/journalsReprints.nav

Permissions: http://www.sagepub.com/journalsPermissions.nav

Citations: http://pid.sagepub.com/content/227/2/139.refs.html

>> Version of Record - Feb 15, 2013

OnlineFirst Version of Record - Aug 16, 2012

What is This? 


\title{
Vehicle dynamics with brake hysteresis
}

Proc IMechE Part D:

J Automobile Engineering

227(2) 139-150

(c) IMechE 2013

Reprints and permissions:

sagepub.co.uk/journalsPermissions.nav DOI: $10.1177 / 095440701245196$ |

pid.sagepub.com

@SAGE

\author{
Barys Shyrokau', Danwei Wang', \\ Klaus Augsburg ${ }^{2}$ and Valentin Ivanov ${ }^{2}$
}

\begin{abstract}
This paper studies hysteresis of vehicle brakes and its influence on the vehicle dynamics. The experimental investigation clearly shows the non-linear and asymmetric characteristics of hysteresis of the disk brakes in passenger cars. A computational model of the brake mechanism with hysteretic elements, based on the Bouc-Wen method, is developed and verified with experimental data. Using the developed model, the influence of hysteresis on the vehicle dynamics during straight-line braking with an anti-lock braking system is analysed. It is also observed that the variations in the hysteresis parameters have important influences on the main vehicle brake characteristics such as the stopping (brake) distance, the time of braking and the average deceleration. A comparative analysis of the simulation results is also given for braking with zero hysteresis or with hysteresis represented as a signal delay and linear function.
\end{abstract}

\section{Keywords}

Brake, hysteresis, Bouc-Wen model, vehicle dynamics

Date received: 22 February 2012; accepted: 28 May 2012

\section{Introduction}

The vehicle dynamics during braking have been extensively researched because of strict vehicle safety requirements. Study of this topic is challenging owing to the wide variation in the road and operational conditions. The majority of related research publications focus on a number of important issues such as road friction estimation, ${ }^{1}$ a longitudinal velocity observer ${ }^{2}$ and combined braking and lateral dynamics. ${ }^{3,4}$ However, brake systems accumulate various additional physical effects that require a clear understanding of their influences on the vehicle behaviour to achieve better performance and safety. The research presented in this paper addresses the brake hysteresis phenomenon as one of these effects. Hysteresis is an attribute of the majority of automotive systems, from the engine to tyres and can be characterized usually by a non-linear and often asymmetric form.

Braking is a key action to ensure the safety and stability of vehicle motion; a reaction delay due to hysteresis can be very critical. In a hydraulic brake system, there are several hysteretic elements such as the vacuum booster, pipelines, valves and brake cylinders. Gerdes and Hedrick ${ }^{5}$ developed a mathematical model of the brake system dynamics using reduced-order models to describe the static hysteresis in a vacuum booster. Augsburg and co-workers investigated relevant tribological processes related to the brake pad behaviour $^{6}$ and the brake pedal feel characteristics. ${ }^{7}$ Tretsiak et al. ${ }^{8}$ carried out experimental investigations of the hydraulic brake components of a lightweight truck and defined the influences of single components (the vacuum booster, disk brake mechanism, brake master cylinder and pipelines) on the value of hysteresis losses. It should be noted that the hysteresis characteristics of the vacuum booster and master cylinder are well known and, owing to their location in the brake drive, have no influence on control systems such as anti-lock braking systems (ABSs) or electronic stability program systems. Garrott and Dunn ${ }^{9}$ investigated the braking performance of medium and heavy trucks and obtained hysteresis plots for an S-cam drum and disk mechanism in an air brake system. Tretsiak ${ }^{10}$ tried to analyse the influence of hysteresis on the vehicle dynamics using a test rig developed at Ilmenau University of Technology. ${ }^{11}$ The test procedure was

\footnotetext{
'EXQUISITUS, Centre for E-City, School of EEE, Nanyang Technological University, Singapore

${ }^{2}$ Ilmenau University of Technology, IImenau, Thuringia, Germany

\section{Corresponding author:}

Barys Shyrokau, Autonomous Robotics Research Laboratory, EXQUISITUS, Nanyang Technological University, Singapore 639798.

Email: barys I@e.ntu.edu.sg
} 


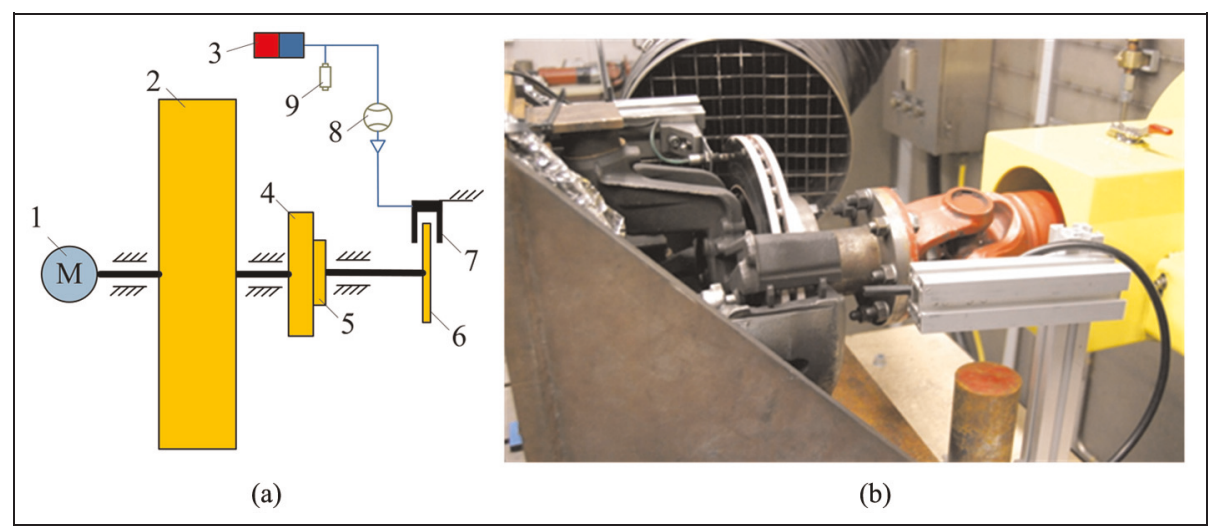

Figure I. (a) Schematic diagram of the test rig: I, motor; 2, inertia disk assembly; 3, air-hydraulic actuating mechanism; 4, inertia hub assembly; 5, rotating torque sensor; 6, brake disk; 7, brake mechanism; 8, flow meter; 9 , pressure sensor. (b) General view of the test rig.

based on the hypothesis that increasing the time of the pressure-holding phase in the ABS algorithm is equivalent to the hysteresis value. However, this approach does not achieve the pure effect of hysteresis. The results show only that the period of the pressureholding phase influences the braking dynamics. Moreover, the characteristics of the brake pressure, which are depicted in another article, ${ }^{12}$ have different levels of maximal brake pressure (the difference is up to $3 \mathrm{MPa}$ ) for the demonstrated investigations. Thus, the increase in the braking distance is caused by the sum of various factors, and not only by hysteresis. Therefore, the assessment of the influence of hysteresis on the vehicle dynamics is not provided in the abovementioned papers.

In studying the vehicle dynamics, the hysteresis is generally represented by a constant time delay, ${ }^{13,14}$ look-up tables ${ }^{15}$ or a linear characteristic (backlash), while in other cases it is neglected. Meanwhile a wide range of hysteresis models have been proposed by Preisach, Duhem, Bouc, Wen and others to correct the behaviour of a mechanical system. For instance, Hoseinnezhad et al. ${ }^{16}$ used the Maxwell-slip model for the hysteresis caused by friction and implemented a real-time calibration technique for the clamp-force model in electromechanical brakes.

The uncontrolled variation in hysteresis during operational conditions complicates its experimental assessment in dynamics. Therefore, a simplified mathematical model of a brake mechanism with hysteretic components is developed in this work and then validated by experiment. The Bouc-Wen method, which is commonly applied for the suspension and dampers, is used as the basis for the development of the mathematical model. After development and validation of the model, the influence of hysteresis on the vehicle dynamics is investigated.

The first objective of this work is to analyse how the effect of hysteresis in a brake mechanism influences the vehicle dynamics and how significant it is for controlled braking. The second objective is to show the difference between representational forms of hysteresis. The methodology described below makes an essential advance in the approach that was first introduced previously by the present authors. ${ }^{17}$

\section{Test rig description and experimental procedure}

This investigation involves experimental testing of the hydraulic brake mechanism of a passenger car to obtain the hysteresis characteristics in the dynamics. For this purpose, a series of tests was carried out using a controlled law of input pressure.

The brake dynamometer test rig, which is situated at the Ilmenau University of Technology, is used to assess the performance and noise testing of hydraulic brakes under different controlled conditions. The schematic diagram and a general view of the dynamometer parts are shown in Figure 1(a) and (b) respectively.

The brake mechanism under study is mounted on the test rig, with its rotation being controlled by the drive system of the test rig with a maximum velocity of up to $2500 \mathrm{r} / \mathrm{min}$. The controlled (input) pressure is generated up to $21 \mathrm{MPa}$ by the air-hydraulic actuating mechanism of the dynamometer. The measurement system included a flow meter, a pressure sensor and a torque sensor. The flow meter is located before the testing brake mechanism and it measures the amount of volumetric displacement. The pressure transducer is used to measure the actual pressure entering the test object. The torque sensor is connected to the inertia hub assembly, and it is isolated from hot or cold environment conditions by a phenolic plate. The measured torque signal is acquired by telemetry and it represents the output torque. The accuracy of the applied sensors is displayed in Table 1.

The pressure law was chosen as a pulse signal with a minimum value and a maximum value of $3.2 \mathrm{MPa}$ and $5.5 \mathrm{MPa}$ respectively, and a frequency of $6 \mathrm{~Hz}$. This is because the width of hysteresis loops in statics is the 
Table I. Accuracy of the measurement system.

\begin{tabular}{|c|c|c|}
\hline \multicolumn{3}{|l|}{ Pressure sensor } \\
\hline $\begin{array}{l}\text { Maximum brake pressure } \\
\text { Accuracy }\end{array}$ & $\begin{array}{l}21 \mathrm{MPa} \\
\pm 0.5 \% \text { full scale }\end{array}$ & $\pm 0.105 \mathrm{MPa}$ \\
\hline \multicolumn{3}{|l|}{ Flow meter (gear type) } \\
\hline $\begin{array}{l}\text { Maximum displacement } \\
\text { Accuracy }\end{array}$ & $\begin{array}{l}50 \mathrm{~cm}^{3} \\
\pm 0.3 \% \text { full scale }\end{array}$ & $0.15 \mathrm{~cm}^{3}$ \\
\hline \multicolumn{3}{|l|}{ Torque sensor (calibration test) } \\
\hline Rated load torque & $5000 \mathrm{~N}$ & \\
\hline \multicolumn{3}{|l|}{ Accuracy } \\
\hline Linearity deviation & 0.004 & \\
\hline $\begin{array}{l}\text { Linearity deviation including } \\
\text { hysteresis }\end{array}$ & 0.006 & \\
\hline Relative hysteresis & 0.011 & $55 \mathrm{~N} \mathrm{~m}$ \\
\hline
\end{tabular}

largest within the middle range of working pressures. This kind of pressure signal corresponds to the braking of a vehicle equipped with an ABS and two-phase relay algorithm (without pressure-holding phase) under wetroad conditions. To reduce measurement noise, three replications were made for each test measurement. The measurement sampling frequency was $10 \mathrm{kHz}$. The initial velocities were $90 \mathrm{~km} / \mathrm{h}$ and $120 \mathrm{~km} / \mathrm{h}$; the contact temperatures of the friction pair of the wheel brake were $100^{\circ} \mathrm{C}$ and $300^{\circ} \mathrm{C}$; the testing modes were the 'instop' mode (free rotation of the brake disk and emulation of emergency braking) and the 'drag' mode (a constant rotational velocity and emulation of service braking).

The experimental results are shown in Figure 2. For plotting purposes, the sampling frequency for three replications was down-sampled using MATLAB with a coefficient of 150 times. The control input pressure is shown in Figure 2(a). The relation between the piston linear displacement and the input pressure is displayed in Figure 2(b). The piston linear displacement is calculated from the volumetric displacement, and the accuracy of the piston displacement is $0.06 \mathrm{~mm}$. It can be seen that hysteresis exists between the phases of increasing pressure and the phases of decreasing pressure. It should be noted that the hysteresis loop is wider in the region of lower pressures than in the region of higher pressures. This confirms that hysteresis has an asymmetric form. Figure 2(c) presents the brake torque versus the linear displacement of the piston. The fluctuation in the brake torque along the linear displacement is non-ordered. Furthermore, the points of one pressure phase overlap those of another phase. This indicates that the relationship between the torque and the displacement has a weak non-linearity due to the apparent fluctuation in the friction coefficient during braking. ${ }^{18}$ Meanwhile the results might include the measurement noise because of the low accuracy of the torque sensor $(55 \mathrm{~N} \mathrm{~m})$. The summarized characteristic

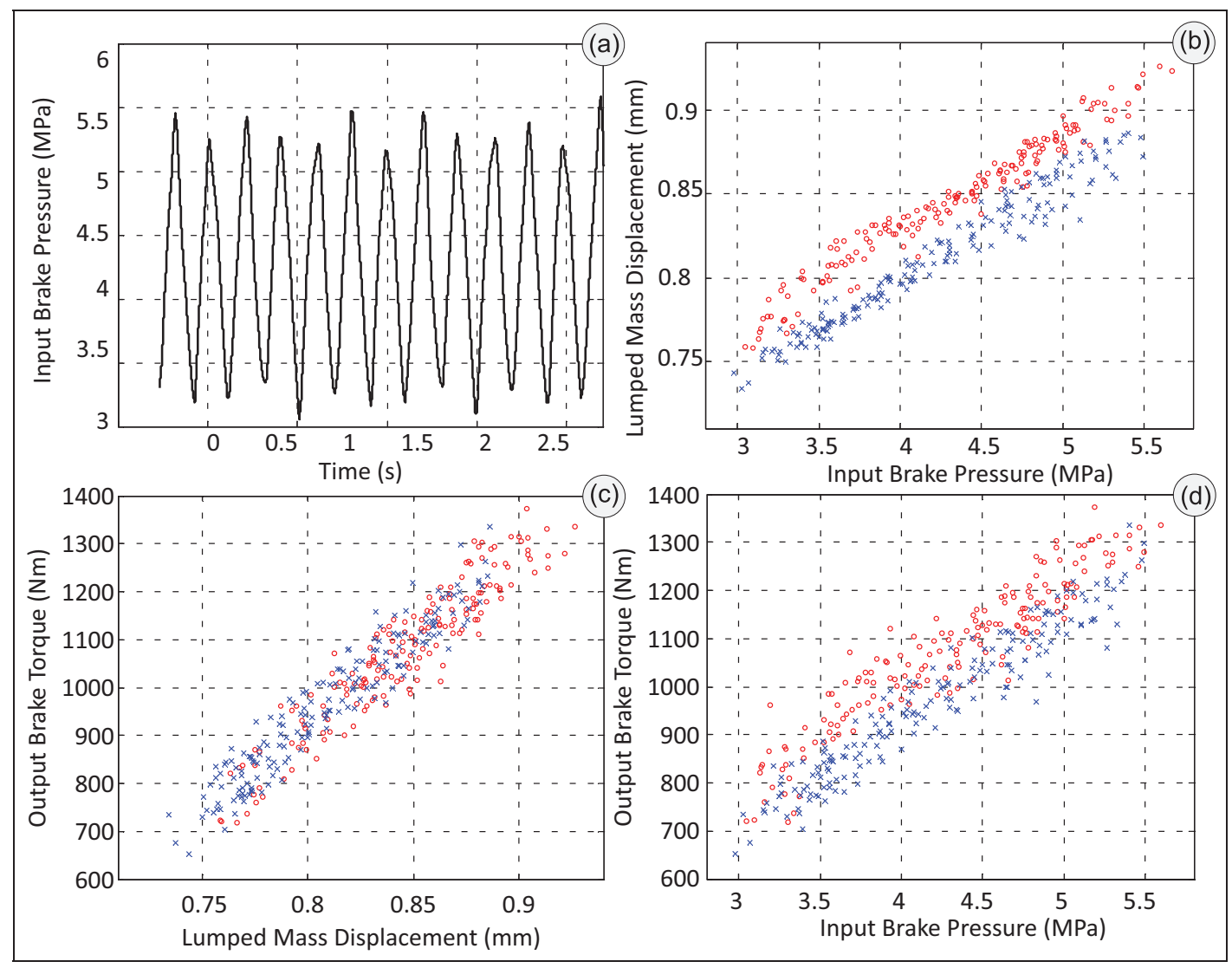

Figure 2. Experimental results of (a) input pressure versus time, (b) piston linear displacement versus input pressure, (c) brake torque versus piston linear displacement and (d) brake torque versus input pressure: $X$, phase of increasing pressure; $O$, phase of decreasing pressure. 
between the input (pressure) signals and the output (torque) signals is shown in Figure 2(d).

\section{Computational model of the brake mechanism and model verification}

In accordance with the experimental results, the hysteresis characteristic is non-linear and asymmetric. Therefore, there is the hypothesis that the representation of hysteresis by a constant shift in the characteristic or in a linear form describes insufficiently the hysteresis effect. The aim of this part of the work under discussion is to develop the mathematical model of the brake mechanism including hysteresis representation and to verify this model with tests.

The dynamic model of the brake mechanism can include the brake rotor, piston and other elements. ${ }^{19,20}$ The model refinement depends on the requirements of the research tasks. In this article, the first objective is the representation of the hysteresis characteristic for the task of vehicle braking dynamics. To reduce the complexity of the mathematical model, a simple mechanical description of the brake mechanism is considered, as shown in Figure 3. One effective way of describing hysteresis is the hysteretic semiphysical model developed by Bouc and generalized by Wen. The Bouc-Wen model has been applied for a huge range of different objects such as magnetorheological dampers and piezoelectric actuators. ${ }^{21}$

In the subsequent discussion, it is assumed that the friction processes are the same for the primary and secondary brake pads. The elements having a translational motion are lumped into one equivalent mass $m_{e q}$. It is represented by the second-order differential equation

$$
m_{e q} \ddot{x}+c_{c} \dot{x}+\Phi\left(\dot{x}, x, z_{1}\right)=u(t)
$$

The control input force is calculated as

$$
u(t)=p(t) \frac{\pi d^{2}}{4}
$$

The contact restoring force $\Phi(x)$, which has a nonlinear and asymmetric behaviour in a 'load-unload' cycle, is described by the modified version of the BoucWen model $^{22}$ as

$$
\Phi(x)=k_{c}\left(x+z_{1}\right)
$$

with

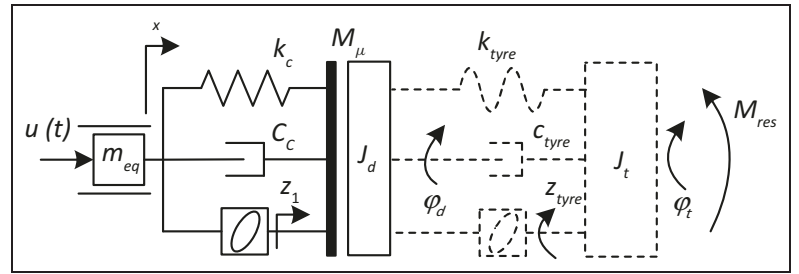

Figure 3. A simplified model of the brake mechanism.

$$
\dot{z}_{1}= \begin{cases}\alpha_{1} \dot{x}-\beta_{1}|\dot{x}| z_{1}\left|z_{1}\right|^{n_{1}-1}-\gamma_{1} \dot{x}\left|z_{1}\right|^{n_{1}}, & \dot{x} \geqslant 0 \\ \alpha_{2} \dot{x}-\beta_{2}|\dot{x}| z_{1}\left|z_{1}\right|^{n_{2}-1}-\gamma_{2} \dot{x}\left|z_{1}\right|^{n_{2}}, & \dot{x}<0\end{cases}
$$

The contact friction torque for the brake mechanism with a fixed caliper is given by

$$
M_{b r}=M_{\mu}=2 \mu(\overline{n v}, \eta) \Phi(x) r_{f r}
$$

The friction coefficient for the brake pads depends on the pressure (the normal force), the temperature and the velocity in contact. During the braking process, the friction coefficient changes dynamically. These dynamics can be modelled by a system of differential equations combining the thermal and mechanical behaviours. For instance, the Ostermeyer ${ }^{23}$ model or the Chichinadze model (as described in the book by Awrejcwicz and $\mathrm{Pyr}^{\prime} \mathrm{yev}^{24}$ ) for the friction coefficient can be applied. The results obtained from these models are sensitive to small variations in the input parameters. Using the Ostermeyer model for a series of braking events, the dynamic friction coefficient is calculated as

$$
\dot{\mu}=-a^{\prime}[(\overline{n v}+\varepsilon) \mu-\eta]
$$

The parameter $\overline{n v}$ is found as

$$
\overline{n v}=\frac{N(t) v(t)}{(N v)_{r e f}}=\frac{\Phi(x) w_{\text {disk }}(t) r_{f r}}{(N v)_{r e f}}
$$

The normalized temperature in the frictional contact is found as

$$
\dot{\eta}=-c^{\prime}\left(\eta-\eta_{0}-\alpha^{\prime} \overline{n v}\right)-\gamma^{\prime}\left(\eta^{4}-\eta_{0}^{4}\right)
$$

To involve the tyre hysteresis (the dashed part of Figure 4), the system of equations can be expanded. In this case, the rotational dynamics are represented as

$$
\begin{aligned}
& J_{d} \frac{\mathrm{d}^{2} \varphi_{d}}{\mathrm{~d} t}=M_{\mu}-c_{\text {tyre }} \Delta \dot{\varphi}-M\left(\Delta \dot{\varphi}, \Delta \varphi, z_{\text {tyre }}\right) \\
& J_{t} \frac{\mathrm{d}^{2} \varphi_{t}}{\mathrm{~d} t}=c_{\text {tyre }} \Delta \dot{\varphi}+M\left(\Delta \dot{\varphi}, \Delta \varphi, z_{\text {tyre }}\right)+M_{\text {res }}
\end{aligned}
$$

where

$$
\Delta \varphi=\varphi_{d}-\varphi_{t}
$$

For test rig experiments, first, the resistance torque is equal to zero and, second, the additional moment $J_{v}$ of inertia, which is equivalent to the vehicle mass, is attached to the required inertia.

The output torque (equivalent tyre torque) is given by

$$
M_{\text {tyre }}=M\left(\Delta \dot{\varphi}, \Delta \varphi, z_{\text {tyre }}\right)=k_{\text {tyre }}\left(\Delta \varphi+z_{\text {tyre }}\right)
$$

with

$$
\dot{z}_{\text {tyre }}=\alpha \Delta \dot{\varphi}-\beta|\Delta \dot{\varphi}| z_{\text {tyre }}\left|z_{\text {tyre }}\right|^{n-1}-\gamma \Delta \dot{\varphi}\left|z_{\text {tyre }}\right|^{n}
$$

The parameters of the proposed model are shown in the Table 2. It was realized in MATLAB/Simulink. The results of model simulation and experiments are 


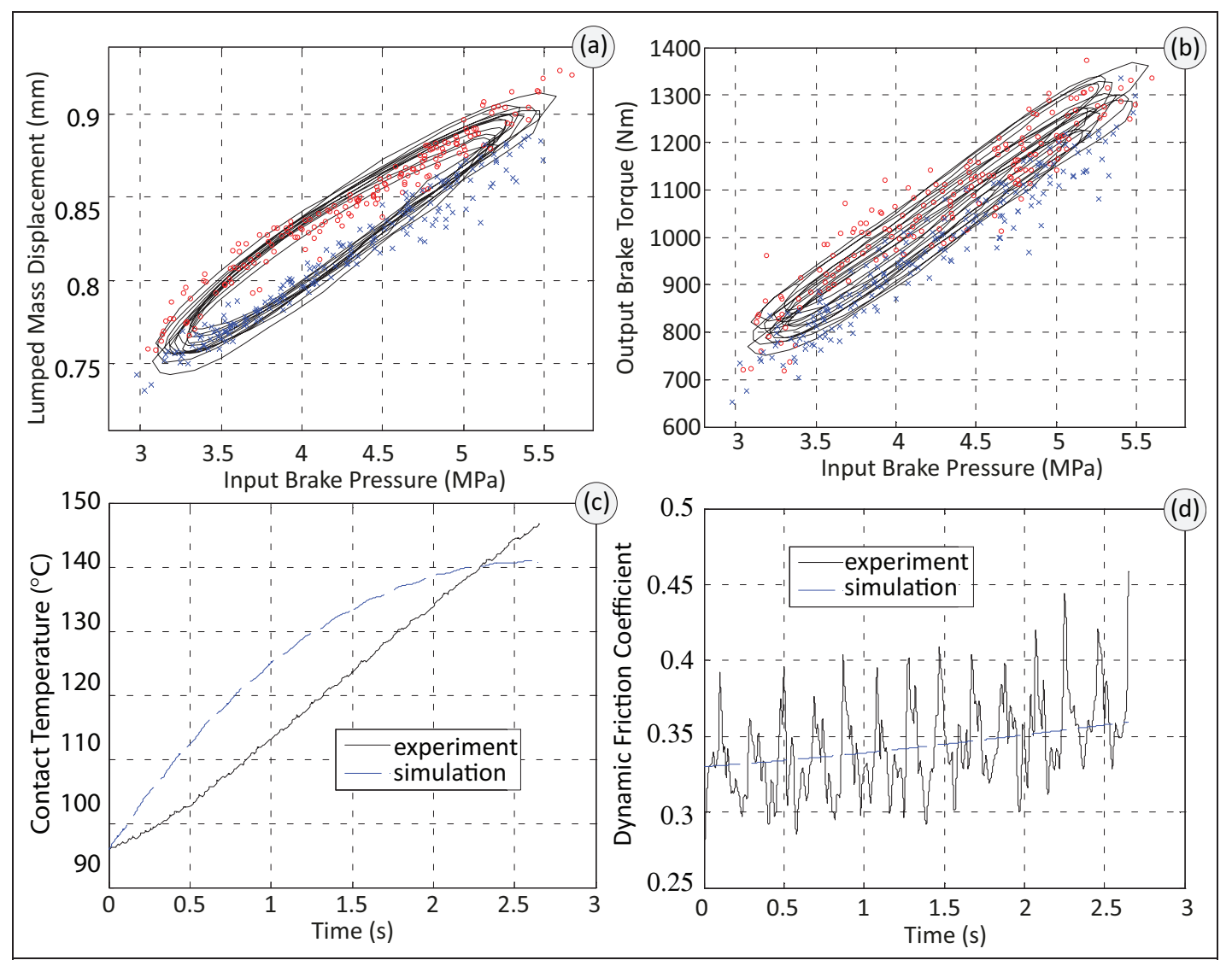

Figure 4. Simulation and experimental results: $\times$, phase of increasing pressure; $\circ$, phase of decreasing pressure.

Table 2. Model parameters.

\begin{tabular}{llll}
\hline Parameters of the proposed model & Value & Parameters of the proposed model & Value \\
\hline Mass of the piston & 0.18 & $n_{1}$ & 0.75 \\
Mass of the pad & 0.24 & $\alpha_{1}=\alpha_{2}$ & 2.0 \\
Piston-cylinder diameter & 0.059 & $\beta_{1}$ & 0.2 \\
Effective radius & 0.13 & $\gamma_{1}$ & 0.5 \\
Inertia moment of the brake disk & 0.11 & $n_{2}$ & 0.65 \\
Actual inertia & 47.46 & $\beta_{2}$ & 4.2 \\
Required inertia & 61.79 & $\gamma_{2}$ & 0.7 \\
Static coefficient of friction & 0.33 & $a^{\prime}$ & 0.1 \\
Translational contact stiffness & $1.35 \times 10^{7}$ & $c^{\prime}$ & 0.3 \\
Translational damping & $2.0 \times 10^{5}$ & $\alpha^{\prime}$ & 0.8 \\
Initial velocity $(\mathrm{rad} / \mathrm{s})$ & 90.42 & $\gamma^{\prime}$ & 0.35 \\
Initial disk temperature $\left({ }^{\circ} \mathrm{C}\right)$ & 96 & $\eta_{0}$ & 0.1 \\
\hline
\end{tabular}

displayed in Figure 4. The input pressure law is the same as shown in Figure 2(a). The influences of the model parameters on the hysteresis characteristic, its area and width are shown in Figure 8 in Appendix 2.

\section{Quarter-model of the vehicle and control algorithm}

The quarter-model of the vehicle with a fixed vertical force is considered to minimize the influences of the load transfer, the change in the wheel radius, etc., on the vehicle dynamics. The mathematical description of the longitudinal dynamics is given by

$$
\begin{aligned}
& m_{a} \frac{\mathrm{d} V_{x}}{\mathrm{~d} t}=-F_{x} \\
& J_{t} \frac{\mathrm{d} \omega_{w}}{\mathrm{~d} t}=-M_{b r}+F_{x} r_{w}
\end{aligned}
$$

The longitudinal force is found from ${ }^{25}$

$$
F_{x}=R_{z}\left[k_{1}\left(1-e^{-k_{2} \cdot s}\right)+k_{3} s\right] \operatorname{sgn}(s)
$$

The slip coefficient can be determined as 
Table 3. Parameters of the simulation model.

\begin{tabular}{lllr}
\hline Parameter (units) & Value & Parameter (units) & Value \\
\hline Vehicle mass $(\mathrm{kg})$ & 480 & $k_{1}$ (road, dry asphalt) & 0.875 \\
Wheel radius $(\mathrm{m})$ & 0.36 & $k_{2}$ (road, dry asphalt) & 34.638 \\
Linear pressure gain & 50 & $k_{3}$ (road, dry asphalt) & 0.143 \\
$K_{p}$ (PID controller) & 3.5 & $k_{1}$ (road, wet asphalt, $0.1 \mathrm{~mm}$ ) & 0.58 \\
$K_{i}$ (PID controller) & 4.2 & $k_{2}$ (road, wet asphalt, 0.1 mm) & 53.81 \\
$K_{d}$ (PID controller) & 0.01 & $k_{3}$ (road, wet asphalt, 0.1 mm) & 0.1 \\
& & $k_{1}$ (road, snow) & 0.214 \\
& & $k_{2}$ (road, snow) & 110.118 \\
& & $k_{3}$ (road, snow) & 0.022 \\
\hline
\end{tabular}

PID: proportional-integral-derivative.

$$
s=\frac{V_{x}-\omega_{w} r_{w}}{V_{x}}
$$

The control algorithm determines the brake pressure. For the purposes of simulations discussed further, the pressure is calculated without brake actuator dynamics (the fluid behaviour in the master brake cylinder, pipelines, valve dynamics, etc.). It is represented as

$$
p(t)=k_{\text {pressure }} \int_{0}^{p_{\max }} r(t) \mathrm{d} t
$$

Two control algorithms are considered: the proportional-integral-derivative (PID) control, which provides two phases of regulation (an increase in the pressure and a decrease in the pressure), and the 'onoff algorithm with an additional pressure-holding phase.

The error between the measured and reference signal is defined as

$$
e=s_{r e f}-|s|
$$

The reference signal of slip is equal to slip under the maximum friction coefficient and it is taken directly from the tyre-road friction model. In general, the choice of reference signal is a complex problem related to road friction identification.

The PID control law has the classical form

$$
r(t)=\left(K_{p} e+K_{i} \int e \mathrm{~d} t+K_{d} \frac{\mathrm{d} e}{\mathrm{~d} t}\right)
$$

The on-off algorithm is based on the thresholds of slip and wheel acceleration. ${ }^{26}$ The additional phases, related to the pressure holding during the build-up phases and the drop phases, are neglected. The parameters of the simulation model are shown in Table 3. The data from Table 2 and the car data from Table 3 relate to the brake test specimen installed on the test rig. The specimen is relevant to the middle-size car under investigation in internal projects.

\section{Influences of the hysteresis parameters on the vehicle dynamics}

The simulation was carried out for three types of road surface (dry asphalt, wet asphalt and snow) with different initial velocities. The parameters of hysteresis model were chosen as for the initial experimental test data from Table 2.

Table 4 illustrates the simulation results. The type of hysteresis shows how the effect of hysteresis is taken into account: 'zero' means that hysteresis is neglected; 'delay' means that a constant transfer delay for the brake torque is applied; 'backlash' means that the hysteresis characteristic is linear and represented as backlash; 'model' means the application of the abovementioned model. The parameters of delay and backlash are chosen so that the maximal widths of hysteresis are the same for all models under braking with an initial velocity of $75 \mathrm{~km} / \mathrm{h}$ and on a wet road.

The hysteresis has more influence on the brake distance and the braking time in the cases of low velocities and slippery roads. This is mainly because the actuation frequency is increased and the total number of regulation cycles is increased. Nevertheless, the average area and maximal width are decreased in comparison with braking on a road with a higher friction coefficient. For dry asphalt, the difference between the zero case and the model case is less than $3 \%$ and, for the slippery road, it is up to $4.5 \%$. The description of hysteresis by delay causes less than $1 \%$ error for all surfaces. The backlash description causes errors of $0.1 \%$ and $5 \%$ for asphalt and snow respectively. In the simulation results, the effect of hysteresis causes an error of less than $5 \%$. However, the parameters of hysteresis were taken for a new brake mechanism. As is known, the area and width of hysteresis can increase during continuous brake operation. Therefore, additional simulation tests related to the variation in hysteresis would be required. The hysteresis loop was expanded using the parameter $\alpha$, and the simulation results are shown in Figure 5 for both control strategies under different velocities and roads. 
Table 4. Simulation results.

\begin{tabular}{|c|c|c|c|c|c|c|c|c|}
\hline Road condition & $V_{x}$ & Hysteresis type & $\bar{A}$ & $w_{\max }$ & $s_{b r}$ & $t_{b r}$ & j & $f_{b r}$ \\
\hline \multirow[t]{8}{*}{ Snow } & \multirow[t]{4}{*}{45} & Zero & - & - & 37.2 & 4.9 & -2.04 & 6.28 \\
\hline & & Delay & 54.1 & 0.373 & 39.1 & 5.2 & -1.94 & 5.29 \\
\hline & & Backlash & 54.4 & 0.548 & 40.7 & 5.4 & -1.87 & 3.89 \\
\hline & & Model & 42.8 & 0.360 & 38.8 & 5.2 & -1.96 & 5.23 \\
\hline & \multirow[t]{4}{*}{60} & Zero & - & - & 66.8 & 6.9 & -2.05 & 5.83 \\
\hline & & Delay & 54.2 & 0.438 & 70.2 & 7.3 & -1.95 & 5.05 \\
\hline & & Backlash & 60.3 & 0.593 & 73.3 & 7.6 & -1.88 & 3.82 \\
\hline & & Model & 44.3 & 0.420 & 69.9 & 7.3 & -1.96 & 4.95 \\
\hline \multirow[t]{8}{*}{ Wet asphalt } & \multirow[t]{4}{*}{75} & Zero & - & - & 41.0 & 3.4 & -5.35 & 4.94 \\
\hline & & Delay & 265.3 & 0.695 & 42.5 & 3.6 & -5.15 & 4.33 \\
\hline & & Backlash & 229.3 & 0.695 & 42.7 & 3.6 & -5.13 & 3.76 \\
\hline & & Model & 212.1 & 0.695 & 42.4 & 3.6 & -5.18 & 4.22 \\
\hline & \multirow[t]{4}{*}{100} & Zero & - & - & 72.4 & 4.7 & -5.39 & 4.57 \\
\hline & & Delay & 259.6 & 0.813 & 75.0 & 4.9 & -5.19 & 3.99 \\
\hline & & Backlash & 249.9 & 0.824 & 75.5 & 4.9 & -5.16 & 3.56 \\
\hline & & Model & 215.0 & 0.828 & 74.8 & 4.9 & -5.21 & 4.01 \\
\hline \multirow[t]{8}{*}{ Dry asphalt } & \multirow[t]{4}{*}{90} & Zero & - & - & 40.4 & 2.9 & -7.91 & 4.38 \\
\hline & & Delay & 499.3 & 0.821 & 41.8 & 3.0 & -7.65 & 3.90 \\
\hline & & Backlash & 416.1 & 0.768 & 41.6 & 2.9 & -7.67 & 3.57 \\
\hline & & Model & 406.7 & 0.857 & 41.6 & 2.9 & -7.68 & 3.91 \\
\hline & \multirow[t]{4}{*}{120} & Zero & - & - & 71.0 & 3.9 & -8.00 & 4.01 \\
\hline & & Delay & 488.8 & 0.993 & 73.2 & 4.0 & -7.74 & 3.63 \\
\hline & & Backlash & 437.9 & 0.956 & 73.1 & 4.0 & -7.75 & 3.39 \\
\hline & & Model & 412.2 & 1.038 & 73.1 & 4.0 & -7.77 & 3.64 \\
\hline
\end{tabular}

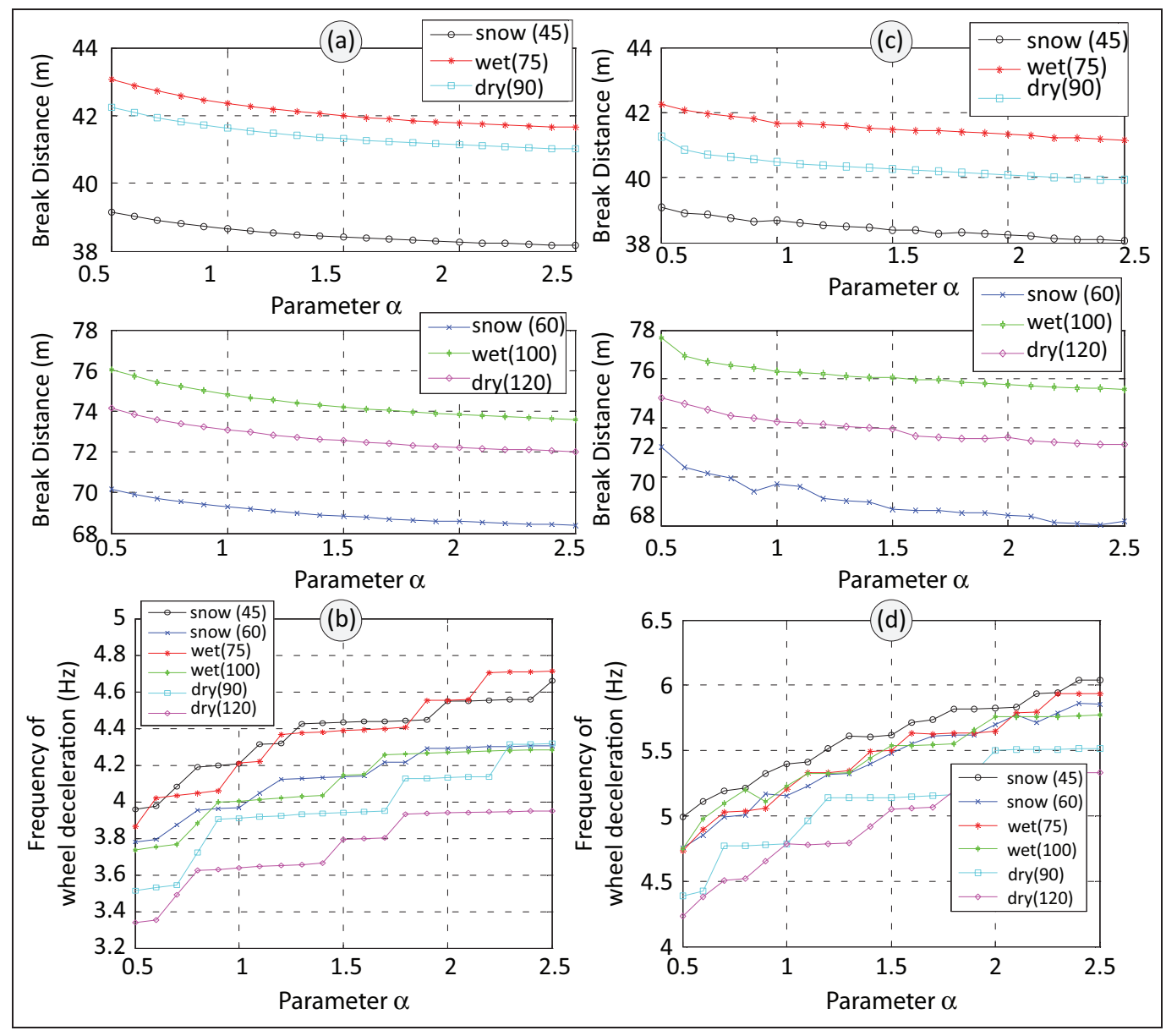

Figure 5. Brake distance and frequency of wheel deceleration versus hysteresis parameter $\alpha$ : (a), (b) for PID control; (c), (d) for on-off control. 


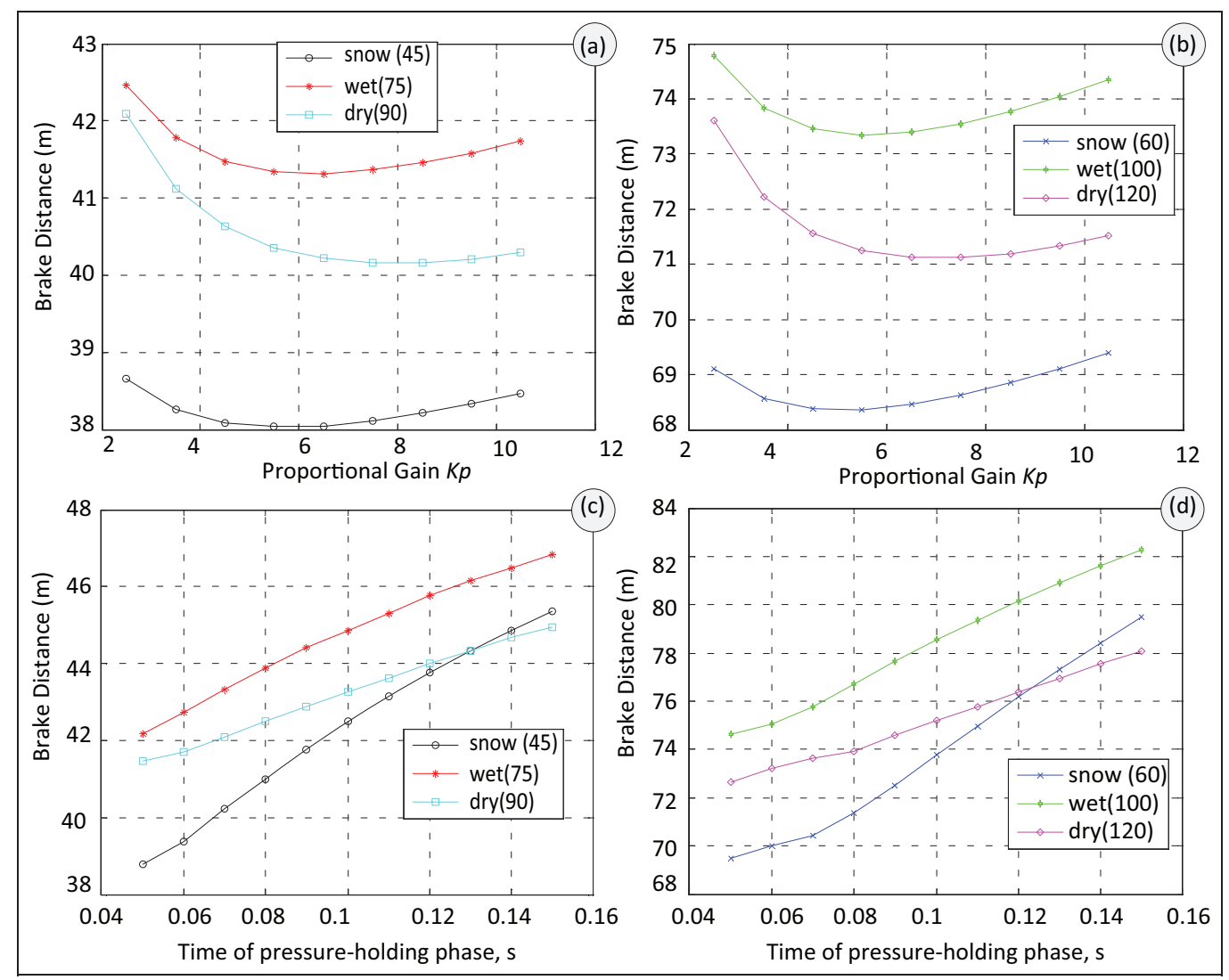

Figure 6. (a), (b) Brake distance versus proportional gain for PID control; (c), (d) brake distance versus time of the pressureholding phase for on-off control.

A higher value of $\alpha$ means that hysteresis is decreased (see Figure 8(a) and (b) in Appendix 2). In Figure 5 it causes a reduction in the brake distance and an increase in the frequency of wheel deceleration simultaneously. The effect has a strong impact and is approximately the same for both control algorithms, namely the PID and the on-off strategies.

One hypothesis is that hysteresis can be controlled by the proportional gain for PID control. For relay control, the issue is how a period of the pressureholding phase is related to the brake distance. Simulations with fixed parameters of hysteresis and variation in the proportional gain for PID control and variation in the time of the pressure-holding phase for relay control were carried out. The simulation results are shown in Figure 6.

The brake distance is initially lower by small values of the proportional gain in the PID controller (until $K_{p}=5$ on average). It is caused by the decreased settling time of the control process. On the other hand, a high proportional gain induces an increase in the average area of hysteresis (Table 4). In addition, the high proportional gain calls for a control overshoot and has a negative influence on the braking performance. The brake distance begins to increase. One of the possible ways to minimize this effect is to increase the derivative coefficient.
For on-off control (Figure 6(c) and (d)) an increase in the time of the pressure-holding phase causes a significant increase in the brake distance. The time of the pressure-holding phase has a greater impact on the brake distance than do the parameters of the hysteresis loop such as the area and the width. The pressureholding phase is usually used to stabilize oscillations in the system. The time of the pressure-holding phase is significant to minimize the consequences of the hysteresis effect; however, it is useless for hysteresis regulation. Apparently, a possible way to improve the brake efficiency and to minimize hysteresis is to utilize a variable pressure rate during ABS cycles.

To check how the representation of hysteresis characteristics influences the vehicle braking, the abovementioned tests were provided for two types of road condition (Figure 7(a) and (b) for snow with an initial velocity of $45 \mathrm{~km} / \mathrm{h}$ and Figure 7(c) and (d) for dry asphalt with an initial velocity of $90 \mathrm{~km} / \mathrm{h}$ ). The neglect of hysteresis causes a monotonic decrease in the brake distance under increasing control frequency, thereby distorting the real system behaviour. The linear representation gives the same behaviour as the zero mode. The delay representation qualitatively shows the same results as the developed model, but the rate of increase in the brake distance is higher under greater proportional gains. 


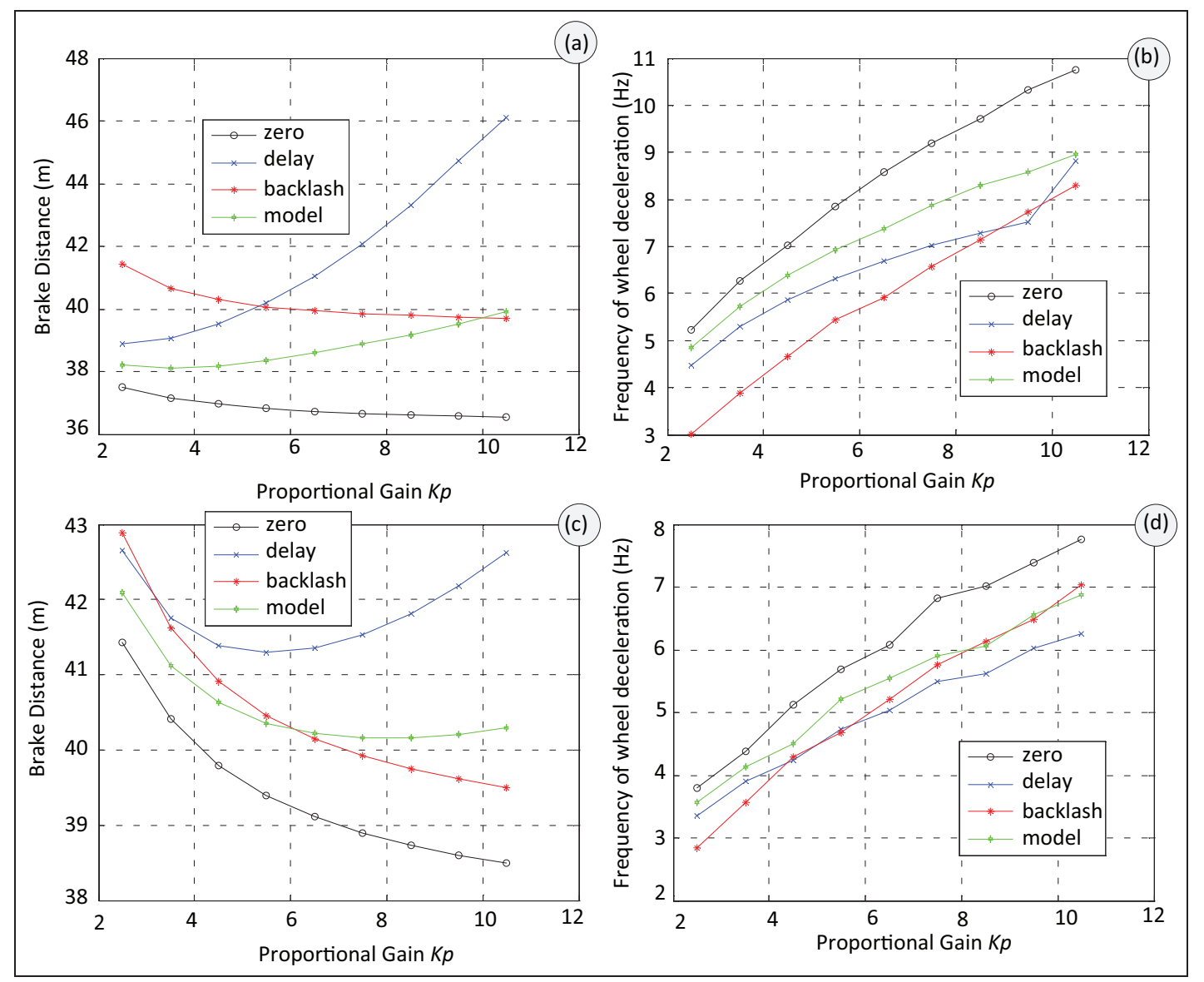

Figure 7. Brake distance and frequency of wheel deceleration versus proportional gain for different representational forms of hysteresis: (a), (b) for snow (45 km/h); (c), (d) for dry asphalt $(90 \mathrm{~km} / \mathrm{h})$.

\section{Conclusions}

Experimental investigations of the disk brake mechanism for a passenger car clearly show a non-linear and asymmetric form of hysteresis. A computational model of the brake mechanism with hysteretic elements, based on the Bouc-Wen method, was developed and verified with the obtained experimental results.

Using the developed model, an analysis of the influence of hysteresis on the vehicle dynamics during straight-line braking with an ABS was provided. The simulation model is a quarter-model of a vehicle with different initial velocities and road conditions. In this article, PID control and on-off relay control with thresholds of slip and wheel acceleration are considered. The influence of the variation in the hysteresis parameters on the main vehicle brake characteristics such as the stopping (brake) distance, the time of braking and the average acceleration are shown. In addition, the results with other ways of hysteresis representation (non-consideration, signal delay and a linear form of hysteresis) are deduced. The relationships of hysteresis and the brake distance versus the proportional gain for PID control and versus the time of the pressure-holding phase for on-off control are shown. The main outcomes of the presented material are as follows.

1. Experimental analysis using a dynamometer test rig confirmed the non-linear and asymmetric form of brake hysteresis.

2. Hysteresis in a brake mechanism influences complex braking manoeuvres, such as braking on slippery roads with high initial velocities or with a sharp change in the friction coefficient, but hysteresis can be neglected during braking from high velocities on a dry road owing to less impact.

3. The analysis shows that the effect of hysteresis on the stopping distance for a new hydraulic disk brake mechanism does not exceed 5\% in most critical cases; however, ignoring this fact can cause incorrect control, e.g. a false demand to increase the control frequency of actuation.

4. To simplify the initial procedures of the ABS and brake design, the influence of the brake hysteresis on the vehicle dynamics can be represented by emulating the hysteresis as signal delay, because it provides sufficient accuracy.

5. The effect of hysteresis on the vehicle dynamics can be controlled by the actuation frequency or the rate 
of brake pressure that improves the adaptive properties of ABS control.

The proposed model can be used for the computational simulation of a brake system to introduce the hysteresis effect into the process of brake torque development. The non-linear behaviour of hysteresis requires a more complex control law to achieve precise tracking of reference signals. The latter issue will be considered in future work

\section{Funding}

This research received no specific grant from any funding agency in the public, commercial or not-for-profit sectors.

\section{Acknowledgements}

The authors are grateful to Sebastian Gramstat and Hannes Sachse for their help with experimental investigations.

\section{References}

1. Patel N, Edwards C and Spurgeon S. Tyre-road friction estimation-a comparative study. Proc IMechE Part D: J Automobile Engineering 2008; 222(12): 2337-2351.

2. Imsland L, Johansen TA, Fossen TI, et al. Vehicle velocity estimation using nonlinear observers. Automatica 2006; 42(12): 2091-2103.

3. Hancock MJ, Williams RA, Gordon TJ and Best MC. A comparison of braking and differential control of road vehicle yaw-sideslip dynamics. Proc IMechE Part D: $J$ Automobile Engineering 2005; 219(3): 309-327.

4. Chung $\mathrm{T}$ and $\mathrm{Yi}$ K. An investigation into differential braking strategies on a banked road for vehicle stability control. Proc IMechE Part D: J Automobile Engineering 2007; 221(4): 443-455.

5. Gerdes JC and Hedrick JK. Brake system modeling for simulation and control. Trans ASME, J Dynamic Systems, Measmt, Control 1999; 121(3): 496-503.

6. Augsburg K, Günther H, Abendroth H and Wernitz B. Comparison between different investigation methods of quasi-static and dynamic brake pad behaviour. SAE paper 2003-01-3340, 2003.

7. Hildebrandt A, Sawodny O, Trutschel R and Augsburg K. Nonlinear control design for implementation of specific pedal feeling in brake-by-wire car design concepts. In: American control conference, Boston, MA, USA, 30 June-2 July 2004, pp.1463-1468. New York: IEEE.

8. Tretsiak D, Kliauzovich S, Augsburg K, et al. Research in hydraulic brake components and operational factors influencing the hysteresis losses. Proc IMechE Part D: J Automobile Engineering 2008; 222(9): 1633-1645.

9. Garrott R and Dunn A. NHTSA research efforts to significantly improve braking performance of medium and heavy trucks. In: 20th international technical conference on the enhanced safety of vehicles conference, Lyon,
France, 18-21 June 2007, paper 07-0242. Washington, DC: National Highway Traffic Safety Administration.

10. Tretsiak D. Experimental investigation of the brake system's efficiency for commercial vehicles equipped with disc brakes. Proc IMechE Part D: J Automobile Engineering, 2012; 226(6): 723-737.

11. Ivanov V, Shyrokau, B and Augsburg K. Model- and hardware-in-the-loop-simulation for problems of bus dynamics control. In: 12th European automotive congress, Bratislava, Slovak Republic, 29 June-1 July 2009, 11 pp. Valencia: STA.

12. Zakharik J, Zakharik A and Tretsiak D. HIL-technology for designing of disk brake mechanisms (in Russian). Gruzovik \& 2010; 10: 30-37.

13. Tao J and Wang B. Study of the dynamic threshold and control logic on anti-lock brake system (ABS). In: Vehicle electronics conference, Changchun, People's Republic of China, 6-9 September 1999, pp.82-85. New York: IEEE.

14. Hardy MSA and Cebon D. Investigation of anti-lock braking strategies for heavy goods vehicles. Proc IMechE Part D: J Automobile Engineering 1995; 209(4): 263-271.

15. Raza H, Xu Zh, Yang B and Ioannou PA. Modeling and control design for a computer-controlled brake system. IEEE Trans Control Systems Technol 1997; 5(3): 279-296.

16. Hoseinnezhad R, Bab-Hadiashar A and Rocco T. Realtime clamp force measurement in electromechanical brake calipers. IEEE Trans Veh Technol 2008; 57(2): 770-777.

17. Shyrokau B, Wang D, Augsburg K and Ivanov V. Modelling and control of hysteresis-characterized brake processes. In: EuroBrake 2012, Dresden, Germany, 16-18 April 2012, paper EB2012-MS-25. Dresden: FISITA.

18. Eriksson $\mathrm{M}$ and Jacobson $\mathrm{S}$. Friction behaviour and squeal generation of disc brakes at low speeds. Proc IMechE Part D: J Automobile Engineering 2001; 215(12): 1245-1256.

19. Leslie AC. Mathematical model of brake caliper to determine brake torque variation associated with disc thickness variation (DTV) input. SAE paper 2004-01-2777, 2004.

20. Bogdevičius M and Vladimirov O. Efficiency of a braking process evaluating the roughness of road surface. Transport 2006; 21(1): 3-7.

21. Ismail M, Ikhouane $\mathrm{F}$ and Rodellar J. The hysteresis Bouc-Wen model, a survey. Arch Comput Meth Engng 2009; 16(2): 161-188.

22. Ni YQ, Ko JM, Wong CW and Zhan S. Modelling and identification of a wire-cable viberation isolater via a cyclic loading test Part 1: an experiment and model developement. Proc IMechE Part I: J Systems and Control Engineering 1999; 213(3): 163-171.

23. Ostermeyer $\mathrm{G}$ On the dynamics of the friction coefficient. Wear 2003; 254(9): 852-858.

24. Awrejcewicz J and Pyr'yev Y. Nonsmooth dynamics of contacting thermoelastic bodies. Berlin: Springer, 2009.

25. Kiencke U and Nielsen L. Automotive control systems for engine, driveline, and vehicle. Berlin: Springer, 2005.

26. BOSCH automotive handbook, 6th edition. Cambridge, MA: Bentley Publishers, 2004. 


\section{Appendix I}

\section{Notation}

$a^{\prime}$

\section{$\bar{A}$}

$c^{\prime}, \alpha^{\prime}, \gamma^{\prime}$

$c_{c}$

$c_{\text {tyre }}$

d

$f_{b r}$

$F_{x}$

$j$

$J_{d}$

$J_{t}$

$J_{v}$

$k_{c}$

$k_{\text {pressure }}$

$k_{\text {tyre }}$

$k_{1}, k_{2}, k_{3}$

$K_{d}$

$K_{i}$

$K_{p}$

$m_{a}$

$m_{e q}$

$M_{\mu}$

$M_{b r}$

$M_{\text {res }}$

$M_{\text {tyre }}$

$\overline{n v}$ empirical parameter which defines the influences of the actual normal load, the actual tangential velocity and the temperature

dimensionless average area of hysteresis during braking

empirical parameters which define

the temperature behaviour

translational damping coefficient

$(\mathrm{N} / \mathrm{m} \mathrm{s})$

rotational damping coefficient

$\left(\mathrm{kg} \mathrm{m}^{2} / \mathrm{s} \mathrm{rad}\right)$

piston-cylinder diameter (m)

frequency of wheel deceleration $(\mathrm{Hz})$

longitudinal force $(\mathrm{N})$

average braking deceleration $\left(\mathrm{m} / \mathrm{s}^{2}\right)$

moment of inertia of the brake disk

$\left(\mathrm{kg} \mathrm{m}^{2}\right)$

moment of inertia of the tyre

$\left(\mathrm{kg} \mathrm{m}^{2}\right)$

moment of inertia, which is

equivalent to the vehicle mass

$\left(\mathrm{kg} \mathrm{m}^{2}\right)$

translational contact stiffness $(\mathrm{N} / \mathrm{m})$

linear pressure gain

rotational contact stiffness $(\mathrm{N} \mathrm{m} /$

$\mathrm{rad})$

empirical parameters depending on

the type of road

derivative gain

integral gain

proportional gain

vehicle mass $(\mathrm{kg})$

lumped mass of elements with

translational motion (piston, pad, etc.) $(\mathrm{kg})$

contact friction torque for the brake

mechanism $(\mathrm{N} \mathrm{m})$

brake torque $(\mathrm{N} \mathrm{m})$

resistance torque from the road

$(\mathrm{N} \mathrm{m})$

equivalent tyre torque $(\mathrm{N} \mathrm{m})$

dimensionless parameter, describing

the actual normal load and actual

tangential velocity in the frictional

contact
$N(t)$

$(N v)_{r e f}$

$p(t)$

$p_{\max }$

$r$

$r_{f r}$

$r_{w}$

$R_{z}$

$S$

$s_{b r}$

$s_{\text {ref }}$

$t_{b r}$

$u(t)$

$v(t)$

$V_{x}$

$w_{\text {disk }}$

$w_{\max }$

$x$

$z_{1}, z_{\text {tyre }}$

$\alpha, \beta, \gamma, n$

$\alpha_{1}, \beta_{1}, \gamma_{1}, n_{1}$,

$\alpha_{2}, \beta_{2}, \gamma_{2}, n_{2}$

$\varepsilon$

$\eta$

$\eta_{0}$

$\mu$

$\phi_{d}$

$\phi_{t}$

$\Phi(x)$

$\omega_{w}$ actual normal load $(\mathrm{N})$

reference system power (W)

input pressure $(\mathrm{MPa})$

maximum brake pressure $(\mathrm{MPa})$

control signal

effective radius of friction (m)

wheel radius (m)

vertical force (in this model, it is

assumed to be constant) (N)

slip coefficient

brake distance $(\mathrm{m})$

reference slip coefficient

stopping time (s)

control input force $(\mathrm{N})$

actual tangential velocity between

the brake pad and the brake disk

$(\mathrm{m} / \mathrm{s})$

longitudinal velocity $(\mathrm{m} / \mathrm{s})$

angular velocity of the brake disk

$(\mathrm{rad} / \mathrm{s})$

dimensionless maximal width of hysteresis during braking

displacement of equivalent mass (m)

hysteretic variables

coefficients describing the hysteresis

in the rotational direction

coefficients to describe hysteresis in

the translational direction

constant dimensionless power

dimensionless parameter for the

temperature in the frictional contact

initial normalized temperature in the

frictional contact

dynamic friction coefficient

angular displacement of the brake

disk (rad)

angular displacement of the tyre

(rad)

contact restoring force $(\mathrm{N})$

angular wheel velocity $(\mathrm{rad} / \mathrm{s})$

\section{Appendix 2}

Figure 8 shows the characteristics and parameters of the hysteresis loop. 


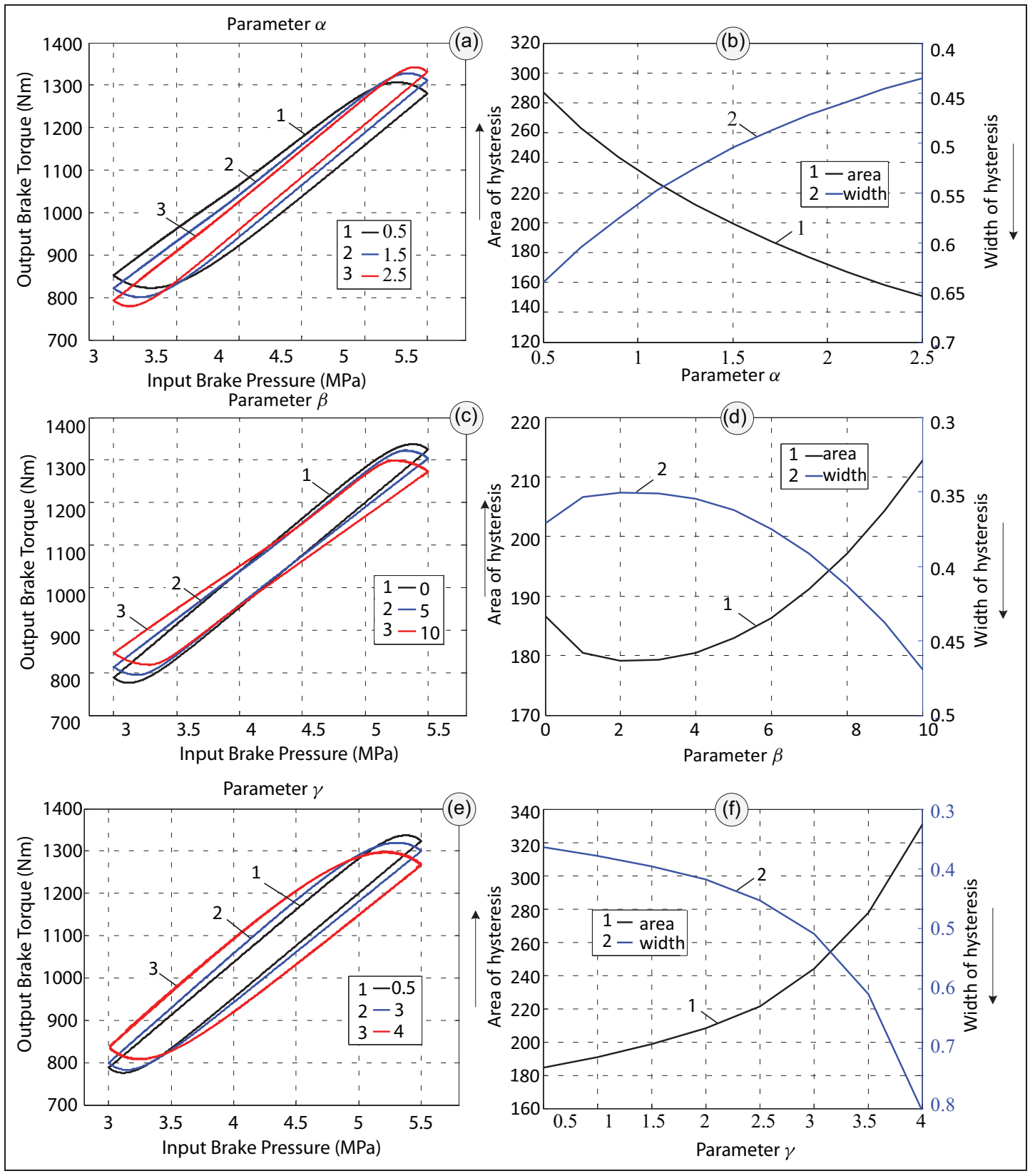

Figure 8. Characteristic and parameters of the hysteresis loop. 